\title{
A Study on FEM Modeling of High-speed Cutting Auto Panel Dies
}

\author{
Jingkui Ruan*, Xueliang Zhou and Peiyao Wang \\ Hubei University of Automotive Technology, Shiyan, Hubei, 442002, China \\ ${ }^{*}$ Corresponding author
}

\begin{abstract}
Finite element method (FEM) is an effective method to study high-speed cutting mechanism. To set up the FEM models of high-speed cutting auto panel dies, large deformation theory and virtual work principle were applied to study high-speed machining process. The finite element governing equation adapted to high-speed machining was achieved. Several key finite element techniques for heat-force coupling in high-speed machining process were studied. The material constitutive equation was established based on the experiments data. The chip separation criterion was applied and the numerical simulation of high-speed cutting auto panel dies was achieved by using DEFORM. In the end, a high-speed cutting case was simulated and the finite element model was proved to be reasonable by analyzing and validating some results of simulation.
\end{abstract}

Keywords-finite element model; auto panel die; high-speed cutting

\section{INTRODUCTION}

Auto panel dies are large and complex equipments for automobile production. MTMoCr is kind of alloy cast iron that is often used to make auto panel dies. High-speed cutting is the most efficient technique to improve the quality and efficiency of machining auto panel dies. The insufficient understanding of high-speed cutting mechanism often leads to improper choice of cutting parameter, serious tool wear, the increase of machining cost and the decrease of productive efficiency. To study the high-speed cutting mechanism by means of experiment needs great effort, and it is especially difficult to measure the cutting temperature, stress and strain. The finite element method (FEM) provides the best approach to solve this problem. The relative movement process of tool against work piece is replayed on the computer. The heat-flow, the phase transformation, the temperature change and the stress distributing are displayed dynamically by FEM and it becomes an efficient method of studying high-speed cutting mechanism [1]. In some researches, a line of separation is predetermined in the front of the tool tip and the chip separates from the basis material along the line when the tool moves forward[2,3,4]. But tools with cutting edge radius can not be simulated in this method, and the physical quantity in the second shear zone can not be determined accurately because of the serious distortion of the meshes. The plane strain orthogonal finite element model of cutting MTMoCr was built, and the process of high-speed cutting was simulated to reveal the mechanism of high-speed cutting. The study result can be used to optimize cutting machining parameters, long tool life and improve machined surface quality.

\section{Methods AND MATERIALS}

The work piece material is the alloy cast iron MTMoCr. A carbon ball-end milling tool with TiAlN coat is adopted, and its diameter is $20 \mathrm{~mm}$, number of teeth is 2 , rake angle is $0^{\circ}$, clearance angle is $22^{\circ}$, cutting edge radius is $0.01 \mathrm{~mm}$. After achieving the mechanical properties of MTMoCr under conditions of high temperature, high strain rate, and high strain by the experiment, the finite element model is established in DEFORM, some key technologies such as the constitutive model of material, chip-tool contact friction, heat-transfer control equation are studied. The distribution of machining temperature and stress and the formation of serrated chip in high-speed cutting MTMoCr are simulated.

\section{A. Establishing the Finite Element Model}

\section{1) The finite element model of orthogonal cutting}

The finish machining of auto panel dies mould surface is completed using hard alloy ball-ended tool on the high-speed machine center. The tool revolves and feeds at the same time in the milling process, and tool moves in a cycloidal trajectory [5]. The distortion in the high-speed cutting process is concentrated in a little deformed area, which reflects the metal cutting law in the deformed zone and is vertical to the cutting edge, is researched to analyze the cutting status of the main cutting edge of the ball-end tool. The cutting depth variety can be neglected because of the high rotate speed of principal axis, so the section can be simplified as the constant thickness chip (Figure I).

The depth of the cutting edge is five times more than the thickness of the cutting layer actually, the moving track of the curve is extended as a line according to the rake angel and the clearance angle of the main cutting edge, and the geometrical model of the orthogonal machining of plain strain is built (Figure II). The deformation process in the cutting area is analyzed taking the orthogonal cutting model.

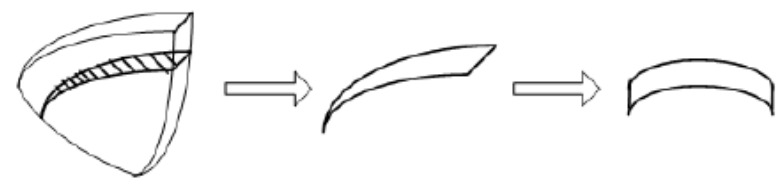

FIGURE I. THE CHIP SECTION SIMPLIFYING 


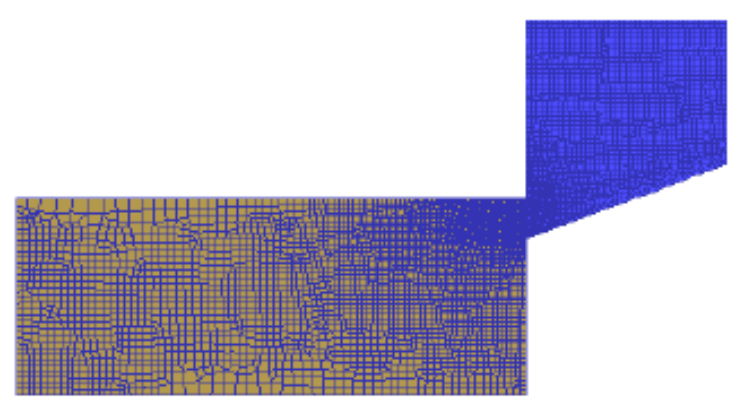

FIGURE II. THE FEM OF ORTHOGONAL CUTTING MACHINING

\section{2) The constitutive model of material}

In the machining process, the flow stress is closely related to the factors such as the equivalent plastic strain of material, strain-rate and temperature when the plastic flow of material occurs. The dynamic mechanical property of $\mathrm{MTMoCr}$ is measured through the quasi-state compress and the high-speed compress experiment to define the flow stress model of material. The quasi-state compress experiment measures the value of the strain and the flow stress by MTS-810 electric/hydraulic servo experimental machine when the temperature are $20^{\circ} \mathrm{C}, 100^{\circ} \mathrm{C}, 200^{\circ} \mathrm{C}$, and $300^{\circ} \mathrm{C}$ and the strain-rate is $0.001 / \mathrm{s}$. The high-speed compress experiment measures the value of the strain and the flow stress using the separated Hopkinson compression bar (SHPB) under conditions of different temperature and different strain-rate (500/s, 1000/s, 2000/s, $3000 / \mathrm{s}, 5000 / \mathrm{s}$ ). The material constitutive model of MTMoCr was built combining with the high-speed compress experiment, which can be seen as follows:

$$
\begin{gathered}
\sigma=\left(522+540 \varepsilon^{0.3}\right)\left(1-0.07 \ln \dot{\varepsilon}+0.0054 \ln ^{2} \dot{\varepsilon}\right)\left[1-\left(\frac{\mathrm{T}-\mathrm{T}_{\mathrm{r}}}{\mathrm{T}_{\mathrm{m}}-\mathrm{T}_{\mathrm{r}}} *\right.\right. \\
\left.\sqrt{\frac{\mathrm{Tm}}{6 * \mathrm{~T}}}^{1.15}\right]
\end{gathered}
$$

here $\sigma$ is yield stress, $\varepsilon$ is equivalent strain, $\dot{\varepsilon}$ is ratio between actual strain rate and quasi-state strain rate, $\mathrm{T}$ is temperature, $\mathrm{T}_{\mathrm{m}}$ is melting point and $\mathrm{T}_{\mathrm{r}}$ is room temperature $\left(20^{\circ} \mathrm{C}\right)$.

\section{3) The chip-tool friction}

The chip-tool contact region can be divided into sliding friction region and sticking friction region. The chip-tool contact can be analyzed throng the normal stress and the friction stress in this region. Whether the friction is sliding or sticking can be determined according to the magnitude of friction force at the chip-tool interface. The perfect way to get friction coefficient in the sliding area is based on the distributed stress data on the tool rake face and the wear on the tool flank face, but it is difficult to measure the stress on the tool rake face in the machining process. Using the cutting force and the feed force, got in the cutting force experiment, to calculate the average friction coefficient provides an appropriate way to solve this problem5.

\section{4) Heat-transfer control equation}

The heat transfer of the metal cutting machining is controlled by the partial differential energy equation in rectangular axis. The heat generation rate in the cutting process has a great effect on the tool wear, the machining surface quality and the residual stress of the work piece. An expression of the volume heat-flow rate caused by the plastic deformation of work piece and the sliding friction at the chip-tool contact is here given:

$$
\dot{\mathrm{Q}}=\frac{1}{\mathrm{~V}} \int_{\mathrm{V}} \bar{\sigma} \dot{\overline{\mathrm{p}_{\mathrm{p}}}} \mathrm{dv}
$$

here $\bar{\sigma}$ is equivalent stress, $\dot{\overline{\varepsilon_{\mathrm{p}}}}$ is the equivalent plastic strain-rate, and $\mathrm{V}$ is the element volume. The heat generated in the metal machining process mostly stays in the first or the second deformation zone. The work piece bears great sheared deformation with high strain-rate in the first deformation zone, so the rise of the temperature in this region is mainly because of the plastic deformation. And the rise of the temperature in the second deformation zone is mainly due to the chip-tool friction. The increment equation expression of heat generation is given as:

$$
\nabla T=\frac{f_{1} f_{2} \bar{\sigma} \partial \bar{\varepsilon}^{p l}}{\rho C_{p}}
$$

here $\nabla \mathrm{T}$ is the temperature increment, $\mathrm{f}_{1}$ is the conversion efficiency factor, $\bar{\sigma}$ is the equivalent stress, and $\partial \bar{\varepsilon}^{\mathrm{pl}}$ is the component of equivalent plastic strain.

\section{B. Simulation of the High Speed Cutting Process}

\section{1) The cutting force simulated and verified}

Testing system of milling force (Figure III) is used to validate the outcome of the FEM. Cutting force is measured on the DMU-70V machining center. The size of the specimen is $150 \mathrm{~mm} \times 100 \mathrm{~mm} \times 50 \mathrm{~mm}$. Kistler $9257 \mathrm{~A}$ measuring instrument is taken as force measuring device. The maximum cutting forces obtained from the FEM and the experiments are shown in table 1. It can be observed in table 1 that there is error between the simulated and the experimental cutting force, the main reasons for the exist of the error are: Firstly, the tool in the finite element model are absolutely sharp rigid body, but the tools are worn in different degree along with the cutting edge in the milling machining process; Secondly, the machine and the tool librates during machining, but the milling simulation performs under the ideal condition; Thirdly, the tool geometry is complicate, so the CAD model of tool needs further improvement.

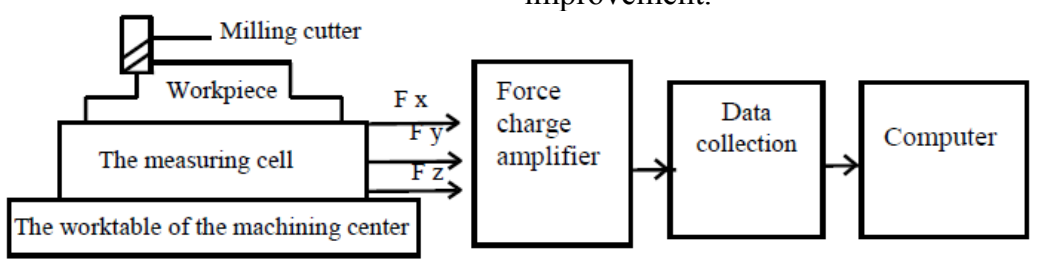

FIGURE III. THE TESTING SYSTEM OF THE CUTTING FORCE 
TABLE I. MACHINING PARAMETERS AND CUTTING FORCE

\begin{tabular}{|l|l|l|l|l|}
\hline Spindle rev [rpm] & 8000 & 9000 & 10000 & 11000 \\
\hline Feed per tooth[mm] & 0.4 & 0.4 & 0.4 & 0.4 \\
\hline Cutting depth[mm] & 0.3 & 0.3 & 0.3 & 0.3 \\
\hline Cutting force(experiment) & 58.75 & 56.76 & 52.32 & 51.62 \\
\hline Cutting force(FEM) & 60.5 & 59.4 & 56.3 & 54.3 \\
\hline Relative error & $2.9 \%$ & $4.4 \%$ & $7.69 \%$ & $4.9 \%$ \\
\hline
\end{tabular}

2) The simulation of cutting temperature

The temperature distribution inside the chip, workpiece and the tool are shown in Figure IV. The cutting temperature on the whole chip-tool interface is higher than in the fist shear zone; The conclusion that the maximum value of the cutting temperature can be got when the chip crack appears and the cutting temperature falls gradually in the stretching part of the crack is the same as Eu-Gene $\mathrm{Ngs}^{[6]}$.

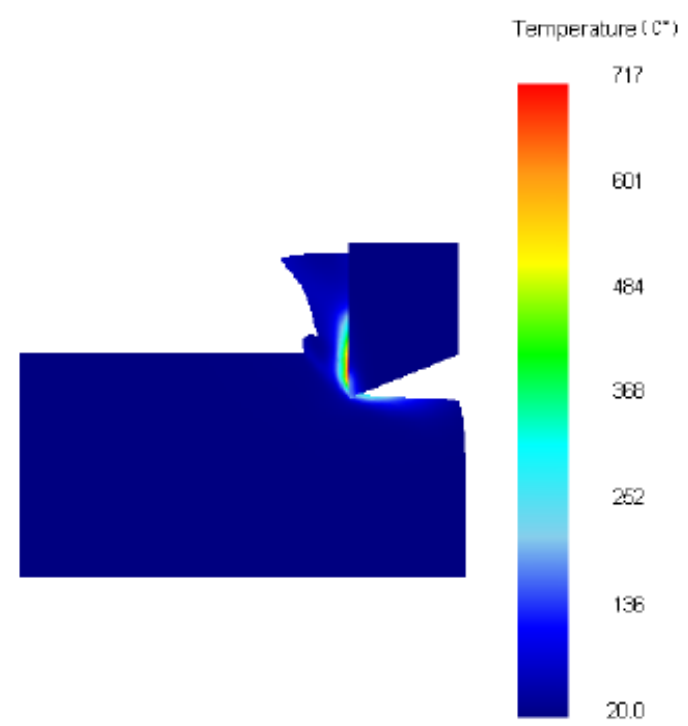

FIGURE IV. THE TEMPERATURE DISTRIBUTION AT 10000RPM

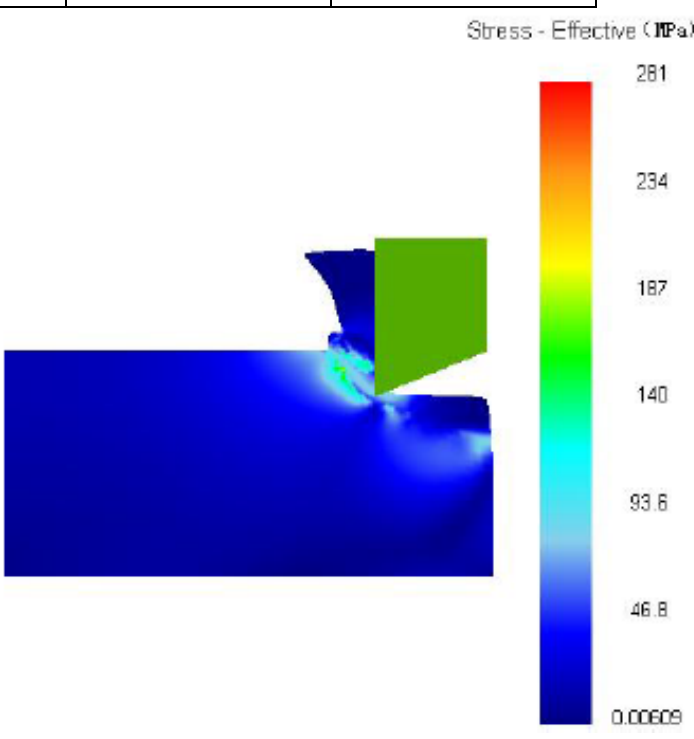

FIGURE V. THE STABLE NORMAL STRESS AT 10000RPM

3) The simulation of normal stress

The normal stress distribution of the chip and the work piece is shown in Figure $V$. The force in the contacting interface of the chip and the tool rake face is compressing stress, and the force in the place except for the contacting interface is pulling stress; secondly, the force inside the work piece near the tool tip is compressing stress, and the compressing stress becomes much less when it is farther from the tool tip; lastly, the force in the interface between the work piece and the flank face is pulling stress, and the compressing stress becomes much less when it is farther from the interface.

4) The simulation of serrated chip formation

In the simulation of the high-speed cutting process, the surface energy of work piece increases, and the element deletion performs when the element energy reach the critical value of fracture, then the work piece material fractures, and the segmented chip come into being gradually. This chip kind can lead to high-frequency periodic wave, the increase of the tool wear and the debasing of the machining surface quality.

The finite element simulation of serrated chip forming process can be seen in Figure VI. A serrated chip is researched to observe the development course of the chip distortion zone. The distortion simulation process of serrated chip element meshes can be seen in Figure VII. 

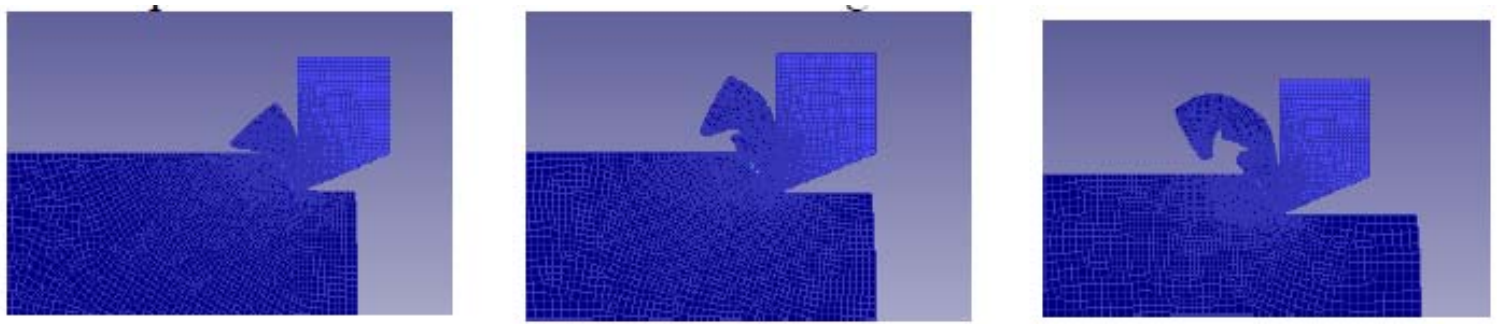

FIGURE VI. THE FORMATION SIMULATION OF SERRATED CHIP
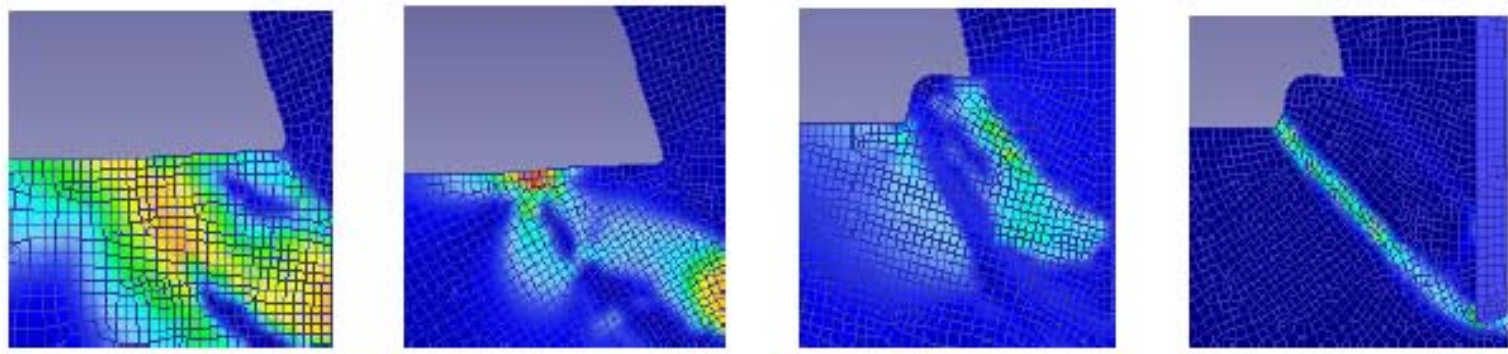

FIGURE VII. THE FINITE ELEMENT MESH DISTORTION OF SERRATED CHIP FORMATION

The start of stress centralization in the unprocessed surface can be seen in the first chart of Figure VIII; the formed crack in the unprocessed surface and the formation of stress centralization can be seen in the second chart of Figure VIII; the formation of the new serrated chip can be seen the third chart; and the formation of the adiabatic shear band when the new serrated chip is forming can be seen in the last chart.

\section{Analysis of Simulation Result}

MTMoCr is high hardness and low heat conductivity which lead to much difficulty to lose the cutting heat, the adiabatic shear band comes into being especially ahead of the tool nose, so it induced the heat balance instability because the high temperature make the local material soften. Along with the cutting, the crack extension initiated which can lead to plastic balance instability because of the crack occurrence caused by the stress concentration owning to the work hardening. The serrated chip of the alloy cast iron materials is the result of adiabatic shear and plastic crack because the serrated chip is caused by the combination of heat balance instability and plastic balance instability. And the serrated chip has great impact on cutting process, for example, the cutting force becomes much larger with larger serrated chip; the tool is easy to be destroyed.

\section{CONCLUSIONS}

The analyses of the cutting force show that it is feasible to analyze the high-speed cutting machining of MTMoCr by using the finite element model. The simulation of chip formation process can forecast the physical quantities such as cutting force, cutting temperature and stress, so it is in favor of discerning the machining mechanism deeply. As a result, the research in this area will impel the development of the researches such as the optimization of the cutting machining technology, the improvement of tool design and the advance of the machined surface qualities.

\section{ACKNOWLEDGEMENT}

This work was supported by automotive power transmission and electronic control key laboratory open foundation of Hubei province of China(No. ZDK1201702).

\section{REFERENCES}

[1] Chong-Yang Gao, Liang-Chi Zhang, Peng-Hui Liu. The role of material model in the finite element simulation of high-speed machining of Ti6Al4V, Proceedings of the Institution of Mechanical Engineers, Part C: Journal of Mechanical Engineering Science. 2016;230(17):2959-2967

[2] Gao, CY, Zhang, LC. Effect of cutting conditions on the serrated chip formation in high-speed cutting. Mach Sci Technol. 2013; 17: 26-40.

[3] Zhang, Y, Umbrello, D, Mabrouki, T. On different FE based models to simulate cutting operation of Titanium alloy (Ti6Al4V). Mechanika. 2013;19: 349-357.

[4] Ruan JK, Gong AH, Zhou XL. Finite Element Simulation of High-Speed Cutting Material MTMoCr. China Mechanical Engineering, 2009;20(11):1372-1375

[5] T. OzelT. Altan. Process simulation using finite element method prediction of cutting forces, tool stresses and temperatures in high-speed flat end milling. International Journal of Machine Tools \& Manufacture, 2000;40(5) :713-738.

[6] Eu-Gene Ng, David K. Aspinwall: Modelling of hard part machining. Journal of Materials Processing Technology, 2002;127(2):222-229. 